\title{
Investments and uncertainty revisited: The case of the US economy
}

\author{
Stavros Degiannakis ${ }^{1}$, George Filis ${ }^{2^{*}}$, George Palaiodimos ${ }^{3}$ \\ ${ }^{1}$ Department of Economics and Regional Development, Panteion University, \\ 136 Syngrou Avenue, GR17671, Athens, Greece. \\ ${ }^{2}$ Bournemouth University, Department of Accounting, Finance and Economics, \\ Executive Business Centre, 89 Holdenhurst Road, BH8 8EB, Bournemouth, UK. \\ ${ }^{3}$ European Central Bank, Directorate of Economics, Fiscal Policy Division, \\ Sonnemannstrasse 20, 60314 Frankfurt am Main, Germany.
}

*Corresponding author: email: gfilis@ bournemouth.ac.uk, tel: 0044 (0) 01202968739, fax: 0044 (0) 01202968833

\begin{abstract}
This paper examines the relationship between investments and uncertainty for the US economy, as the latter is approximated by consumer sentiment, purchasing managers' prospects and economic policy uncertainty. Contrary to the existing literature, we provide evidence that this relationship is time-varying. The time variation is attributed to the observed temporal replacement effect between private and public investments. Furthermore, we show that there are two distinct correlation regimes in this relationship and unless we concentrate on them, we cannot fully unravel the real link between uncertainty and investments. Finally, we examine whether the use of the two correlation regimes provides better forecasts for investments compared to the use of the uncertainty indices alone. The forecasting exercise reveals that the use of correlation regimes provides statistically superior outof-sample forecasts.
\end{abstract}

JEL codes: C32, C51, C53, E22, H50.

Keywords: Uncertainty, public investments, private investments, gross fixed capital formation, dynamic correlation, forecast. 


\section{Introduction}

Politicians and international institutions make decisions that alter the way through which economies operate and interact. This is particularly topical in the light of the recent recession and financial crisis, the European sovereign debt crisis and the rising US fiscal deficit, when politicians assumed a bold role in stabilizing and shaping the world economy. In this regard, there is a significant degree of uncertainty as to what tools can be used by policy makers and institutions, what impact these decisions will have on the economy and how timely they will be.

Evidence suggests that when faced with such uncertainty, US corporations choose to reduce capital investment (Rodrick 1991; Bloom et al., 2007; Baum et al., 2008). Another usual case is when the press media attribute a reduction in corporate investment partly to increased policy uncertainty ${ }^{1,2}$. In the same context, both the European Investment Bank (2013) and the IMF (2015) conclude that economic and policy uncertainty has been the most important immediate cause of low investment in Europe. They report that sectors of the economy that are more sensitive to uncertainty experience a larger fall in investment relative to the less sensitive sectors during times of high economy wide uncertainty.

Furthermore, several theoretical studies have established mechanisms through which higher uncertainty may cause lower investment rates. First, Bernanke (1983) and Rodrik (1991), among others, argue that if investment projects are not fully reversible, uncertainty will increase the benefit of the option to wait until more information of the projects is revealed. Second, uncertainty exaggerates the costs of external financing by increasing default risk (e.g. Gilchrist et al., 2014) or the equity risk premium (Pástorand Veronesi, 2013), which can lead to investment contraction. Overall, this strand of the literature supports the current census of the constant linkage between higher uncertainty and investment decline.

In empirical terms, the work of Aizenman et al. (1993), Episcopos (1995) and Asteriou et al. (2005) provide evidence of a significant negative relationship between uncertainty and investment, thereby confirming the aforementioned theoretical studies.

\footnotetext{
${ }^{1}$ See, for example, "Investment Falls Off a Cliff: U.S. Companies Cut Spending Plans Amid Fiscal and Economic Uncertainty" (Wall Street Journal, November 19, 2012).

${ }^{2}$ For a complete list of articles relating economic policy uncertainty with economic performance see: http://www.policyuncertainty.com/media.html.
} 
Despite a plethora of evidence on the effects of uncertainty on fixed assets investments, no study has examined the potential time-varying relationship between the aforementioned variables. The assumption of a time-varying correlation between uncertainty and various macroeconomic variables has only recently received substantial attention in the literature (for instance, relating policy uncertainty and stock market returns - see, Antonakakis et al., 2013; Kang and Ratti, 2013; Lean and Nguyen, 2014; Alexopoulos and Cohen, 2015, among others). However, there is still a growing interest in understanding the real economic effects of uncertainty. This study adds to this growing literature showing that the use of the time-varying correlation unravels the full dynamics of the relationship between investments and uncertainty.

In studying the relationship between uncertainty and investments, there is the critical issue of how to measure and quantify uncertainty. This task is rather complicated. Several data sources and a wide range of indicators have been generally used in the literature to capture uncertainty, including data from consumer and business surveys. Verifying whether these data and indicators capture what they are supposed to capture is an important issue. Thus, apart from the examination of the uncertainty and investments in a time-varying environment, this study also attempts to provide an answer as to which uncertainty measure is the best leading indicator for the US investments.

Overall, the paper contributes to the literature of uncertainty and investments, focusing on the interrelations between different types of uncertainty and fixed assets investments rather than stock market investments, in the US economy. We take a disaggregate view on private and governmental (or public) investment, using three potential sources of uncertainty, namely, consumer, business and policy uncertainty. To do so, we make use of the consumer sentiment indicator, the purchasing managers' index and the recently developed economic policy uncertainty index of Baker et al. (2013). Finally, we produce a forecasting exercise in order to establish which uncertainty indicator(s) can produce better forecasts of fixed assets investments.

The results show that the relationship is indeed time-varying and there are two distinct correlation regimes. Furthermore, we report that Consumer Sentiment Index is the best leading indicator for the US investment, followed by Policy Uncertainty Index. More importantly, we reveal that the incorporation of the time-varying 
correlation effects provide statistically superior out-of-sample forecasts of US investments.

Our investigation, apart from the obvious policy implications that are particularly important to the current recessionary phase of the global economy, provides a yardstick for nowcasters and forecasters that seek a well-chosen leading indicator for US investments.

The remaining of the paper is structured as follows. In section 2 we describe the data used in this study. Section 3 illustrates the methodology used for the estimation of the time-varying correlation. Section 4 analyses the empirical findings and Section 5 concludes the study.

\section{Data description}

The employed data include the consumer sentiment indicator (CSI), the purchasing managers' index (PMI) and the economic policy uncertainty index (PUI), which represent our uncertainty indices, and the gross fixed capital formation as a percentage of GDP (Investments), which approximates the level of US investments. We disentangle the total investments into private and governmental in order to examine the potential heterogeneous attitude of uncertainty on the private and the public sector's investment activity. Our sample runs from 1985:Q1 to 2014:Q3. Investments are in constant terms. Data on the CSI and PMI are obtained from Federal Reserve Economic Data, on Investments from Datastream ${ }^{\circledR}$ and on PUI from Baker et al. (2013). Figure 1 shows the evolution of the series.

\section{[FIGURE 1 HERE]}

From Figure 1, panel A, we observe that the CSI and PMI indices tend to fluctuate in parallel, whereas the opposite holds for the PUI index. This is particularly noticeable during the early-2000, as well as, during the Great Recession of 20072009. An analogous pattern is also met after 2012, as the declining trend of PUI is supported by a rebound of the real economy sentiment indicators, i.e. CSI and PMI. Still following the EMU sovereign crisis right after the 2007-2009 US recession, real economy sentiment did not follow the rising economic policy uncertainty.

This may suggest that the real sector uncertainty was resolved fairly quickly after the end of the Great Recession, while economic policy uncertainty persisted until 2012, possibly mirroring EMU uncertainty and an anaemic growth of the US economy. Another interesting observation is that during economic recessions we find 
the opposite behaviour between private and public investments, which is suggestive of a substitution effect between these spending items.

\section{Methodology}

In order to investigate the time-varying correlation between investment and sentiment indicators, we define a bivariate framework for the dynamic estimation of their variance-covariance matrix. The $\mathbf{y}_{t}=\left(y_{t}^{(n)} x_{t-i}^{(m)}\right)^{\prime}$ vector denotes the ratio of investment to GDP, $y_{t}^{(n)} \equiv G F C F_{t}^{(n)} / G D P_{t}$, and the sentiment indicator, $x_{t-i}^{(m)}$, at a quarterly frequency $t$. For $n=1,2,3$, the $G F C F_{t}^{(n)}$ variable expresses the total, governmental and private investments, respectively. For $m=1,2,3$, the sentiment indicators are the CSI, PMI and PUI indices, respectively ${ }^{3}$. The sentiment indicators are available on a monthly frequency. The PMI, ESI and CSI indices are computed as the moving average of the six most recent monthly observations. In many instances, in order to go from monthly to quarterly frequency, it is preferable to simply take the last monthly observation in the quarter. However, due to the highly volatile nature of the sentiment series we choose the moving average approach, which reduces the volatility, while maintaining the information extracted from the series. The lag order of $x_{t-i}^{(m)}$ is the $i$ that maximizes the cross correlation between $y_{t}^{(n)}$ and $x_{t-i}^{(m)}$. The proposed framework is:

$$
\begin{aligned}
\mathbf{y}_{t} & =\boldsymbol{\beta}_{0}+\boldsymbol{\varepsilon}_{t} \\
\boldsymbol{\varepsilon}_{t} & =\mathbf{H}_{t}^{1 / 2} \mathbf{z}_{t} \\
\mathbf{z}_{t} & \sim N(\mathbf{0}, \mathbf{I}) \\
\mathbf{H}_{t}=\sigma\left(\mathbf{H}_{t-1},\right. & \left.\mathbf{H}_{t-2}, \ldots, \boldsymbol{\varepsilon}_{t-1}, \boldsymbol{\varepsilon}_{t-2}, \ldots\right),
\end{aligned}
$$

where $\boldsymbol{\beta}_{0}$ denotes the mean of $\mathbf{y}_{t}$, and $\mathbf{z}_{t}$ is a bivariate normally distributed process with $E\left(\mathbf{z}_{t}\right)=\mathbf{0}$ and $E\left(\mathbf{z}_{t} \mathbf{z}_{t}^{\prime}\right)=\mathbf{I}$. The demeaned vector of $\mathbf{y}_{t}$, or $\boldsymbol{\varepsilon}_{t}$, has a conditional variance-covariance matrix $\mathbf{H}_{t}$. The variance-covariance matrix $\mathbf{H}_{t}$ is estimated in a Diag-VECH framework according to Bollerslev's et al. (1988) specification ${ }^{4}$ :

\footnotetext{
${ }^{3}$ All variables are stationary and the test statistics are available upon request.

${ }^{4}$ The vech (.) operator stacks the columns of a $(n \times n)$ square matrix from the diagonal downwards in a $(n(n+1) / 2) \times 1$ vector. The symbol $\circ$ denotes the Hadamard (elementwise) product.
} 


$$
\operatorname{vech}\left(\mathbf{H}_{t}\right)=\operatorname{vech}\left(\mathbf{A}_{\mathbf{0}}\right)+\sum_{j=1}^{q}\left(\operatorname{vech}\left(\mathbf{A}_{j}\right) \circ \operatorname{vech}\left(\boldsymbol{\varepsilon}_{t-j} \mathbf{\varepsilon}_{t-j}^{\prime}\right)\right)+\sum_{j=1}^{p}\left(\operatorname{vech}\left(\mathbf{B}_{j}\right) \circ \operatorname{vech}\left(\mathbf{H}_{t-j}\right)\right) \text {. }
$$

According to Degiannakis et al. (2013) we do not include lags of the endogenous variables in the conditional mean, as the non-diagonal elements of the variance-covariance matrix would express the time-varying correlation of the residuals; and in such case we would have estimated the time-varying correlation of the unexplained part of the endogenous variables.

The time varying correlation between $y_{t}^{(n)}$ and $x_{t-i}^{(m)}$ is estimated as:

$$
\rho_{t}^{(n, m)}=\frac{\sigma_{t}^{(n, m)}}{\sqrt{\sigma_{t}^{2(n)} \sigma_{t}^{2(m)}}}
$$

where $\sigma_{t}^{2(n)}$ and $\sigma_{t}^{2(m)}$ are the diagonal elements of $\mathbf{H}_{t}$, and $\sigma_{t}^{(n, m)}$ is the non-diagonal element of $\mathbf{H}_{t}$.

An asymmetric form of the Diag-VECH model, a leptokurtically distributed $\mathbf{z}_{t}$ process, and the lag orders $p, q$ are investigated according to the standard statistical criteria. The Diag-VECH specification is preferable compared to models with large time varying covariance matrices; i.e. Engle's (2002) DCC model. Moreover, it involves the estimation of a lower number of parameters than other multivariate GARCH models; i.e. Engle and Kroner's (1995) BEKK model, Engle's et al. (1986) VECH model, etc. For technical information see Xekalaki and Degiannakis (2010).

\section{Results}

\subsection{Time-varying correlations}

The results of the time-varying correlations between investments and uncertainty indicators are shown in Figure 2. Given the fact that higher CSI/PMI reflects lower uncertainty, whereas the reverse holds true for PUI, we rely on the theoretical evidence of a positive (negative) correlation between investments and CSI and PMI (PUI).

\section{[FIGURE 2 HERE]}

Contrary to the existing theoretical and empirical evidence, we observe that all correlations fluctuate in both the negative and positive areas and they are, indeed, time-varying. It is clear that two regimes exist in the relationship between the 
uncertainty indicators and investments. This holds for all three uncertainty indicators. Thus, examining the aforementioned relationship in a static framework masks some important regime changes, which could provide additional feedback to policy makers.

Another interesting observation is that these correlations exhibit heterogeneous patterns for different uncertainty indicators. For instance, looking at the total investments (top panel) during the 1990s recession, we notice that correlations with the PMI and PUI are negative, whereas a zero correlation exists with CSI. Moreover, during the early 2000 recession, correlations are all positive. It is only during tranquil periods and the Great Recession that the expected positive (negative) correlations with the CSI and PMI (PUI) are reported (Figure 2).

Turning our attention to the correlations regarding the governmental and private investments, the following regularities are observed. First, the governmental correlations resemble the patterns of the total investments correlations, which is expected as the main component of investments is the private one. Second, there is evidence of a replacement effect between governmental and private investments. For instance, the correlations between CSI and governmental (private) investments are mainly negative (positive). The reverse holds true for the PUI. This replacement effect may suggest a more active Keynesian countercyclical public investment policy stance aiming to avoid recessionary phases of the economic circle. The last observation from the middle and lower panels in Figure 2 is that the picture is quite unclear in the case of PMI, which may suggest that PMI is not a credible leading indicator for US investments.

\subsection{Time-varying correlation regimes and the best leading indicator}

In an attempt to identify the best leading indicator for the US investments and check robustness of previous findings the following model is estimated:

$$
y_{t}^{(n)}=\gamma_{0}+\gamma_{1} d\left(\rho_{t}^{(n, m)}>0\right)+\gamma_{2} x_{t-i}^{(m)}+\gamma_{3} d\left(\rho_{t}^{(n, m)}>0\right) x_{t-i}^{(m)}+e_{t},
$$

where $e_{t} \sim N\left(0, \sigma_{e}^{2}\right)$ and $d\left(\rho_{t}^{(n, m)}>0\right)$ is a dummy variable that takes the value of one when the time-varying correlation is positive and the value of zero otherwise. The use of a dummy variable aims to quantify the differential inter-linkages between uncertainty and investment as implied by the two different regimes previously observed (Figure 2). The results are shown in Table 1.

[TABLE 1 HERE] 
From Eq. (4) we notice that the use of the two regimes offers significant information for the US investments (see Table 1). More specifically, the interaction terms provide evidence of a change in the relationship between uncertainty and investments, where in regime 1 (i.e. positive correlation) the effect of uncertainty on investments is positive (i.e. $\gamma_{2}+\gamma_{3}$ ), whereas in regime 2 (i.e. negative correlation) the effect is negative (i.e. $\gamma_{2}$ ). Finally, the adjusted coefficient of determination suggests that the best leading indicator is CSI, followed by PUI, whereas PMI performs poorly (as also depicted by Figure 2).

In order to verify further the aforementioned results we proceed with an outof-sample forecasting exercise based on Eq. (4). More specifically, the scope of the forecasting exercise is twofold. First, to establish whether the use of the two regimes in the time-varying correlation between uncertainty and investments offers a better predictive ability compared to the direct effects of uncertainty on investments. Second, whether CSI and PUI are indeed the best leading indicators for the US investments.

Eq. (4) is estimated in its full version incorporating the time-varying correlation effect, as well as in its nested version, with $\gamma_{1}=0$ and $\gamma_{3}=0$, taking into consideration only the information provided by the uncertainty indicators. The initial training period of the models is $\tilde{T}=60$ quarters, i.e. from 1985Q1 until 1999Q4. For the period 2000Q1 to 2014Q3 (i.e. the remaining $T=59$ quarters), the one-quarterahead forecasts of $y_{t}^{(n)}$, for $n=1,2,3$, are estimated. In order to proceed to the first out-of-sample forecast (i.e. $t+1$ forecast or 2000Q1) we train the models using the initial 60 quarters. For each following out-of-sample forecast we add to the training period an additional quarter. For example, for the $t+2$ forecast we use $\tilde{T}+1$ quarters. Thus, at each quarter, the models are re-estimated based on all past information set available. The forecasting accuracy of the models is gauged using three established loss functions, namely the MSE, MAE and MAPE, as shown in Table 2.

\section{[TABLE 2 HERE]}

Table 3 reports the three forecasting evaluation criteria for the two different forecasting models, whereas Figure 3 depicts the actual and forecasted investments. The results provide evidence that the forecasts produced by CSI outperform these produced by PMI or PUI for all cases apart from government investments. 
Interestingly enough, it is PMI that generates the best forecasts in this instance. More importantly, it is evident that the use of correlation regimes improves the forecasting accuracy in all cases. A close competitor of CSI is PUI, where in most cases (apart from governmental investments) it seems to provide the second best forecasts. Thus, we maintain that CSI is indeed the best leading indicator, followed by PUI. Finally, we provide evidence that the use of correlation regimes has the capacity to improve forecasting accuracy significantly.

\section{[TABLE 3 HERE]}

\section{[FIGURE 3 HERE]}

In order to investigate further i) which leading indicator and ii) whether the time-varying correlation effect provide statistically more accurate forecasts, we utilize the Model Confidence Set (MCS) procedure of Hansen et al. (2011). The MCS procedure defines the models that perform the best predictions, where best is defined in terms of the MSE, MAE and MAPE loss functions. We compare the prediction accuracy of the initial set of the six models for each $y_{t}^{(n)}$. The Eq. (4) in its full and nested version for the three leading indicators defines the set of the six models. For $M^{0}$ defining the initial set of the six models, $L_{i, t}$ denoting the loss function of model $i$ at quarter $t$, and $d_{i, j, t} \equiv L_{i, t}-L_{j, t}$ is the evaluation differential for $i, j \in M^{0}$, the hypotheses that are being tested are:

$$
H_{0, M}: E\left(d_{i, j, t}\right)=0
$$

for $\vee i, j \in M, M \subset M^{0}$ against the alternative $H_{1, M}: E\left(d_{i, j, t}\right) \neq 0$ for some $i, j \in M$

. The prediction accuracy of $M^{0}$ set of models is investigated, at a predefined level of significance, and explores which models survive the elimination algorithm. The elimination algorithm based on an equivalence test and an elimination rule, employs the equivalence test for investigating the $H_{0, M}$ for $\forall M \subset M^{0}$ and the elimination rule to identify the model $i$ to be removed from $M$ in case that $H_{0, M}$ is rejected.

Table 4 presents the MCS p-values. The MCS $p$-values are analogous to that of a classical $p$-value; a $(1-a)$ confidence interval that contains the true parameter with a probability no less than $(1-a)$. The MSC p-values clearly suggest that i) the CSI leading indicator as well as ii) the incorporation of the time-varying correlation effects provide statistically superior forecasts of US investments. 
[TABLE 4 HERE]

\section{Conclusion}

The aim of this study is to assess empirically for the first time the relationship between uncertainty and investments from a macroeconomic perspective for the case of the US economy. Three different sources of uncertainty are employed, namely, the CSI, PMI and PUI indices. The findings show that the relationship between investments and uncertainty does not always follow the general anecdotal temporal principles of positive and negative correlations depending on the source of uncertainty. This is an important finding, which provides evidence that the relationship between investment and uncertainty is rather complex and it is both time depended and driven by economic cycles. Furthermore, we reveal that governmental investments exhibit a countercyclical behavior, whereas a pro-cyclical behavior is observed for the private investments. This differential behavior is informative of a significant substitution-crowding out effect between these different instruments. Finally, our findings suggest that compared to PMI, CSI and PUI are better leading indicators for the US investments. Finally, the MSC test provides evidence that the regression model with the CSI uncertainty measure and the time-varying correlation effects provide statistically superior forecasts of total, private and governmental US investments.

\section{Acknowledgement}

We would like to thank the editor Mark Taylor and the reviewer for their constructive comments and suggestions which helped us to improve the scope and clarity of the paper. We would also like to thank David Duffy and the participants of the Accounting, Finance and Economics Research Group workshop at the University of Ulster for providing us with valuable suggestions in a previous version of the paper. The views expressed here are those of the authors and do not necessarily reflect those of the European Central Bank (ECB). The authors are solely responsible for any remaining errors and deficiencies. 


\section{References}

Aizenman, J. \& Marion N.P., (1993). Policy Uncertainty, Persistence and Growth. Review of International Economics, Vol. 1, Issue 2.

Alexopoulos, M. \& Cohen, J. (2015). The power of print: Uncertainty shocks, markets, and the economy. International Review of Economics \& Finance, online first.

Antonakakis, N. \& Chatziantoniou, I., \& Filis, G. (2013). Dynamic co-movements of stock market returns, implied volatility and policy uncertainty. Economics Letters, 120(1), 87-92.

Asteriou, D. \& Price S., (2005). Uncertainty, Investment and Economic Growth: Evidence from a Dynamic Panel. Review of Development Economics, 9(2), 277288.

Baker, S.R., Bloom, N. \& Davis, S.J. (2013). Measuring economic policy uncertainty. Chicago Booth research paper, (13-02).

Baum, C.F., Caglayan, M. \& Talavera, O. (2008). Uncertainty determinants of firm investment. Economics Letters, 98(3), 282-287.

Bernanke, B.S., (1983). Irreversibility, uncertainty, and cyclical investment. Quarterly Journal of Economics, 98 (1), 85-106.

Bloom, N., Bond, S. \& Van Reenen, J. (2007). Uncertainty and investment dynamics. The Review of Economic Studies, 74(2), 391-415.

Bollerslev, T., Engle, R.F. \& Wooldridge, J.M. (1988). A Capital Asset Pricing Model with Time-Varying Covariances. Journal of Political Economy, 96, 116131.

Degiannakis, S., Filis, G., \& Floros, C. (2013). Oil and stock returns: Evidence from European industrial sector indices in a time-varying environment. Journal of International Financial Markets, Institutions and Money, 26, 175-191.

Engle, R.F. (2002). Dynamic Conditional Correlation: A Simple Class of Multivariate GARCH Models. Journal of Business and Economic Statistics, 20, $339-350$

Engle, R.F. \& Kroner, K.F. (1995). Multivariate Simultaneous Generalized ARCH. Econometric Theory, 11, 122-150.

Engle, R.F., Granger, C.W.J. \& Kraft, D. (1986). Combining Competing Forecasts of Inflation Using a Bivariate ARCH Model. Journal of Economic Dynamics and Control, 8, 151-165. 
European Investment Bank (2013). Investment and Investment Finance in Europe, Luxembourg.

Episcopos, A. (1995). Evidence on the relationship between uncertainty and irreversible investment. The Quarterly Review of Economics and Finance, $35(1), 41-52$.

Gilchrist, S., Sim, J. W. \& Zakrajšek, E. (2014). Uncertainty, financial frictions, and investment dynamics (No. w20038). National Bureau of Economic Research.

Hansen, P.R., Lunde, A. \& Nason, J.M. (2011). The model confidence set, Econometrica, 79, 456-497.

International Monetary Fund (2015). Private Investment: What's the holdup?.In World Economic Outlook-Short and Long term factors.

Kang, W. \& Ratti, R. A. (2013). Oil shocks, policy uncertainty and stock market return. Journal of International Financial Markets, Institutions and Money, 26, 305-318.

Lean, H.H. \& Nguyen, D. K. (2014). Policy uncertainty and performance characteristics of sustainable investments across regions around the global financial crisis. Applied Financial Economics, 24(21), 1367-1373.

Pástor, L. \& Veronesi, P. (2013). Political uncertainty and risk premia. Journal of Financial Economics, 110(3), 520-545.

Rodrik, D. (1991). Policy uncertainty and private investment in developing countries. Journal of Development Economics, 36 (2), 229-242.

Xekalaki, E. \& Degiannakis, S. (2010). ARCH Models for Financial Applications, John Wiley \& Sons Ltd., New York. 
Figures \& Tables

Figure 1: Variables under investigations. Sample runs from 1985:Q1 - 2014:Q3. Panel A: Uncertainty indices

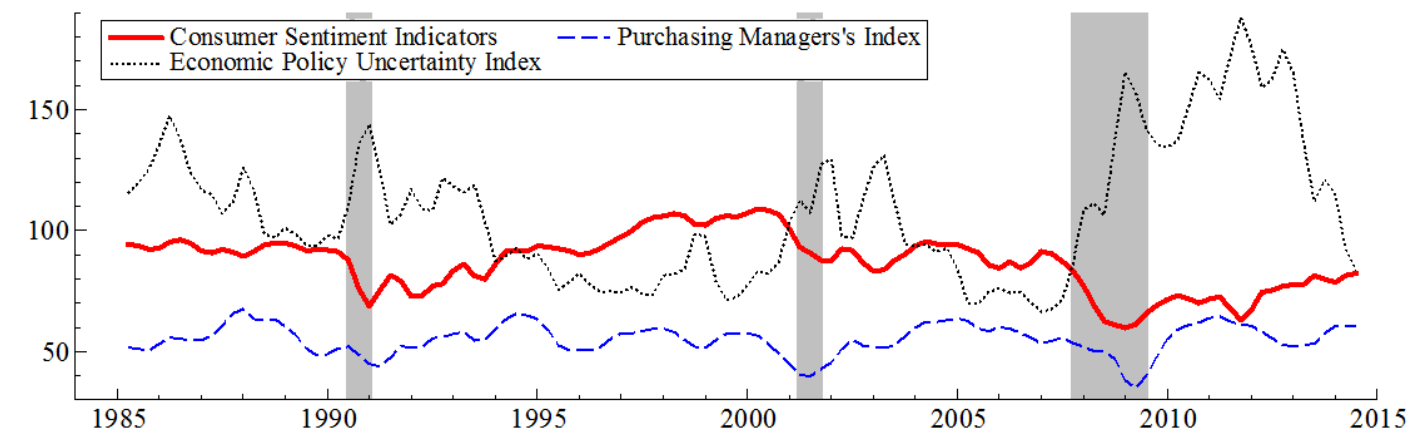

Panel B: US Investments (\% GDP)
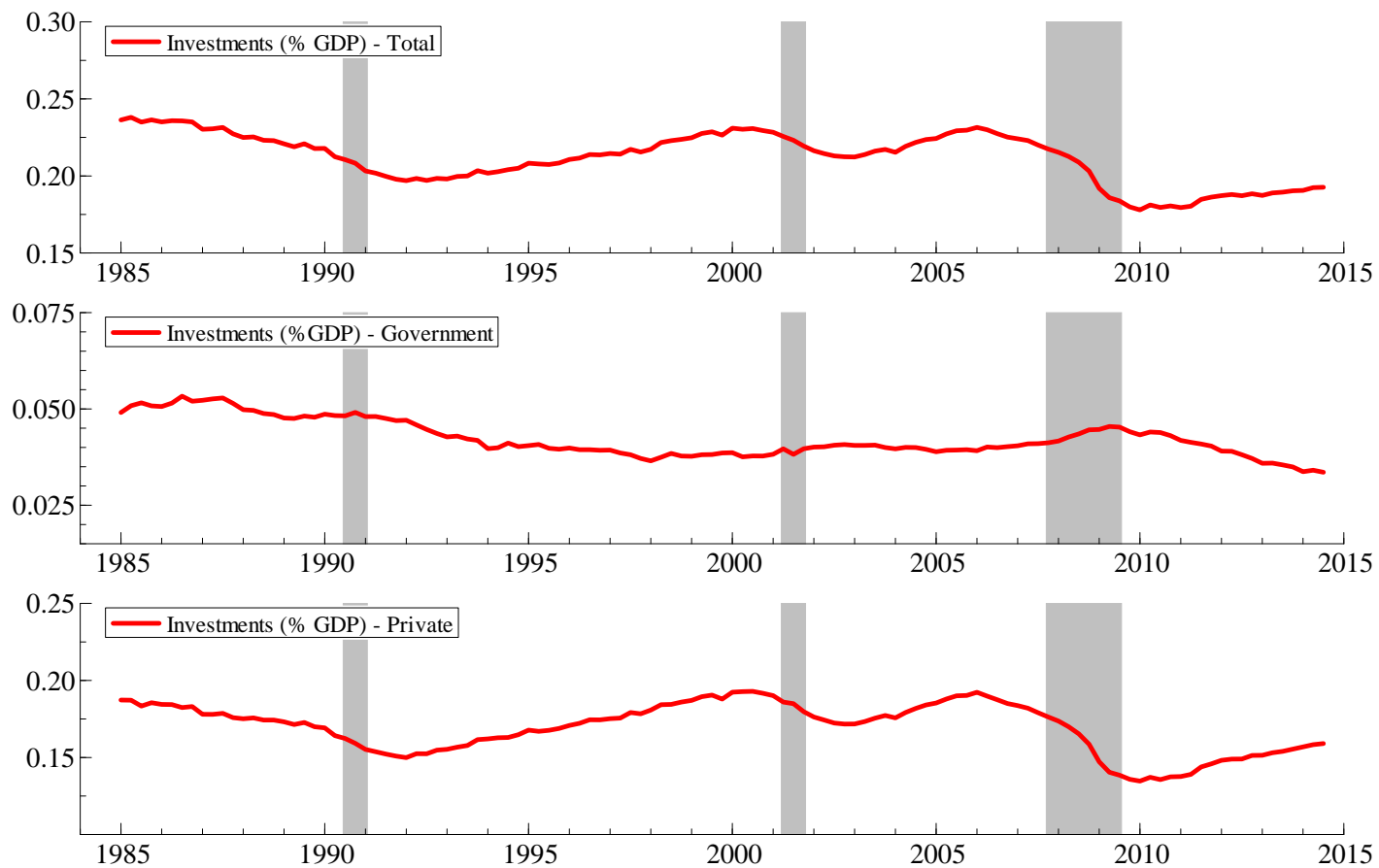

Note: Shaded areas denote US recessions as defined by NBER 
Figure 2: Time-varying correlations between investments and the three sources of uncertainty. The sample runs from 1985:Q1 - 2014:Q3.
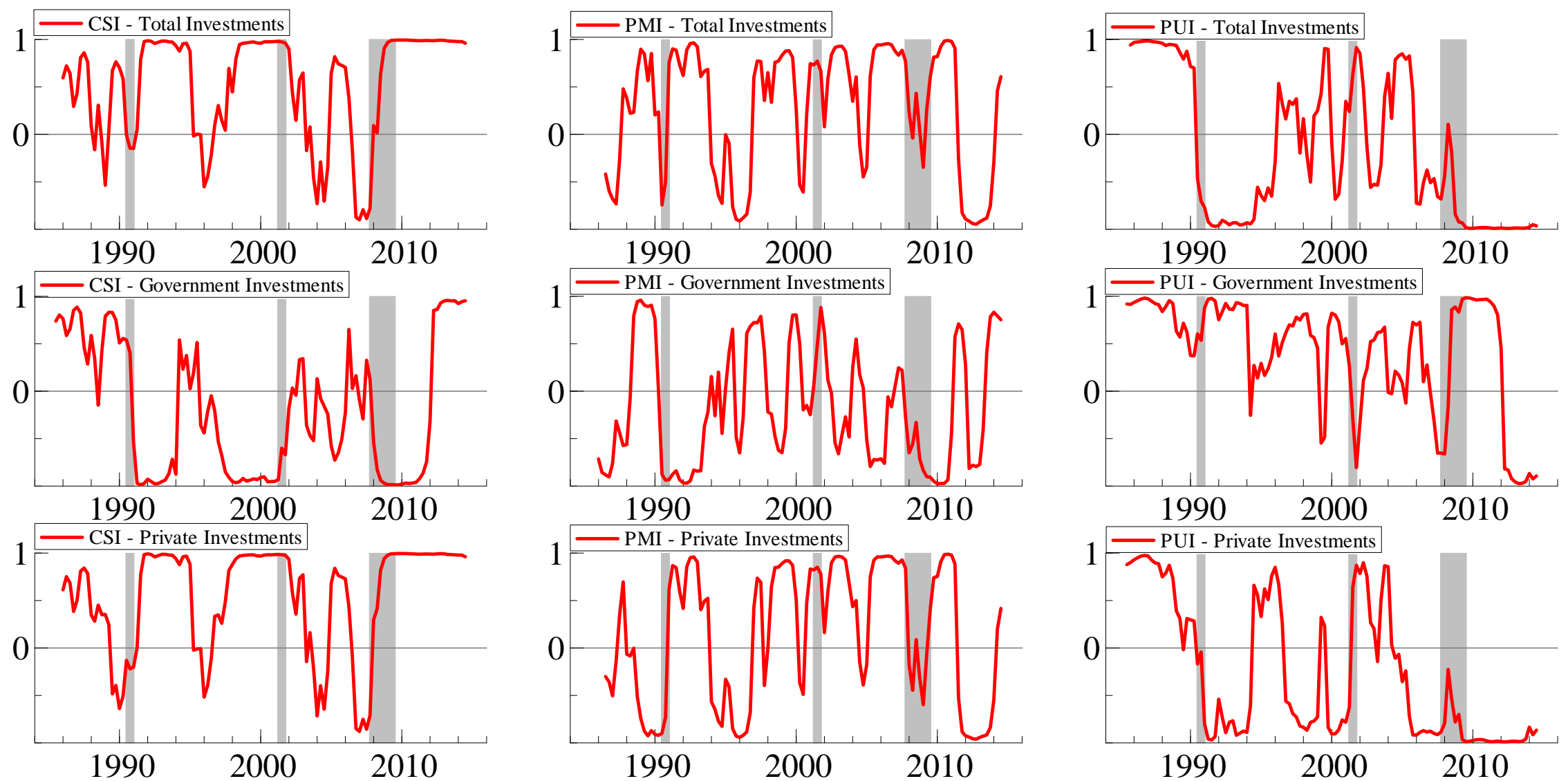

Note: Shaded areas denote US recessions as defined by NBER. 
Figure 3: One-quarter ahead forecasts for total, government and private investments.

Without correlation regimes


Table 1: Regression results from equation (4).

\begin{tabular}{|c|c|c|c|c|c|c|c|c|c|}
\hline \multirow{2}{*}{$\begin{array}{l}\text { Dependent Variable: } \\
\text { Independent Variables: }\end{array}$} & \multicolumn{3}{|c|}{ Total Investments } & \multicolumn{3}{|c|}{ Governmental Investments } & \multicolumn{3}{|c|}{ Private Investments } \\
\hline & $(1)$ & (2) & (3) & (4) & (5) & (6) & (7) & $(8)$ & (9) \\
\hline \multirow[t]{2}{*}{ Constant } & $0.30120 *$ & $0.32366^{*}$ & $0.24827 *$ & $0.05506^{*}$ & $0.06040^{*}$ & $0.04214 *$ & $0.28703 *$ & $0.21458 *$ & $0.21614^{*}$ \\
\hline & $(0.04639)$ & $(0.04743)$ & $(0.00602)$ & $(0.00263)$ & $(0.00659)$ & $(0.00166)$ & $(0.03981)$ & $(0.03418)$ & $(0.00689)$ \\
\hline \multirow[t]{2}{*}{ CSI_Investments_dummy } & $-0.19488^{*}$ & & & $-0.07117^{*}$ & & & $-0.22630^{*}$ & & \\
\hline & $(0.04688)$ & & & $(0.01581)$ & & & $(0.04046)$ & & \\
\hline \multirow[t]{2}{*}{$C S I_{t-i}$} & $-0.00094 * * *$ & & & $-0.00016^{*}$ & & & $-0.00126^{*}$ & & \\
\hline & $(0.00052)$ & & & $(0.00003)$ & & & $(0.00045)$ & & \\
\hline \multirow[t]{2}{*}{ CSI_Investments_dummy $\times C S I_{t-i}$} & $0.00213^{*}$ & & & $0.00084^{*}$ & & & $0.00249 *$ & & \\
\hline & $(0.00053)$ & & & $(0.00018)$ & & & $(0.00045)$ & & \\
\hline \multirow[t]{2}{*}{ PMI_Investments_dummy } & & $-0.18959 *$ & & & $-0.03607 *$ & & & $-0.14193 *$ & \\
\hline & & $(0.05181)$ & & & $(0.01117)$ & & & $(0.04111)$ & \\
\hline \multirow[t]{2}{*}{$P M I_{t-i}$} & & $-0.00203 * *$ & & & $-0.00032 *$ & & & -0.00082 & \\
\hline & & $(0.00084)$ & & & $(0.00012)$ & & & $(0.00060)$ & \\
\hline \multirow[t]{2}{*}{$P M I \_I n v e s t m e n t s \_d u m m y \times P M I_{t-i}$} & & $0.00348 *$ & & & $0.00061^{*}$ & & & $0.00267 *$ & \\
\hline & & $(0.00092)$ & & & $(0.00020)$ & & & $(0.00073)$ & \\
\hline \multirow[t]{2}{*}{ PUI_Investments_dummy } & & & $-0.04190 *$ & & & -0.00671 & & & $-0.05892 *$ \\
\hline & & & $(0.00867)$ & & & $(0.00412)$ & & & $(0.00958)$ \\
\hline \multirow[t]{2}{*}{$P U I_{t-i}$} & & & $-0.00040^{*}$ & & & $-0.00003 *$ & & & $-0.00046^{*}$ \\
\hline & & & $(0.00005)$ & & & $(0.00001)$ & & & $(0.00006)$ \\
\hline \multirow[t]{2}{*}{ PUI_Investments_dummy $\times P U I_{t-i}$} & & & $0.00056^{*}$ & & & $0.00011 *$ & & & $0.00063 *$ \\
\hline & & & $(0.00009)$ & & & $(0.00004)$ & & & $(0.00009)$ \\
\hline$F$-statistic & $136.08210^{*}$ & $23.07614 *$ & $134.97490 *$ & $50.91862 *$ & $11.85673 *$ & $18.35055^{*}$ & $206.43300 *$ & $20.09402 *$ & $88.38170^{*}$ \\
\hline Adjusted $R^{2}$ & 0.78045 & 0.37159 & 0.77753 & 0.56351 & 0.22222 & 0.30974 & 0.84390 & 0.33838 & 0.69324 \\
\hline
\end{tabular}
used. The CSI lags in specifications (1), (4) and (7) are 3,1 and 3, respectively. The PMI lags in specifications (2), (5) and (8) are 5,3 and 5 respectively. The PUI lags in 
specifications (3), (6) and (9) are 2, 1 and 1, respectively. The choices of lags were based on the lag structures used in the time-varying correlations estimations. 
Table 2: Loss functions for the evaluation of forecasting accuracy.

\begin{tabular}{ll}
\hline Loss functions & Formula \\
\hline $\begin{array}{l}\text { Mean squared error } \\
\text { (MSE) }\end{array}$ & $M A E=T^{-1} \sum_{t=1}^{T}\left|y_{a, t}^{(n)}-y_{f, t}^{(n)}\right|$ \\
$\begin{array}{l}\text { Mean absolute error } \\
\text { (MAE) }\end{array}$ & $M S E=T^{-1} \sum_{t=1}^{T}\left(y_{a, t}^{(n)}-y_{f, t}^{(n)}\right)^{2}$ \\
$\begin{array}{l}\text { Mean absolute percentage error } \\
\text { (MAPE) }\end{array}$ & MAPE $=T^{-1} \sum_{t=1}^{T}\left|\frac{y_{a, t}^{(n)}-y_{f, t}^{(n)}}{y_{a, t}^{(n)}}\right| \times 100$ \\
\hline $\begin{array}{l}\text { Note: } y_{f, t}^{(n)} \text { denotes the forecasted value of } y_{t}^{(n)}, \text { whereas } y_{a, t}^{(n)} \text { denotes its actual } \\
\text { value. }\end{array}$ \\
\hline
\end{tabular}


Table 3: Forecasting accuracy tests: One quarter ahead

\begin{tabular}{llcccccccc}
\hline & \multicolumn{3}{c}{ CSI based forecast } & \multicolumn{3}{c}{ PMI based forecast } & \multicolumn{3}{c}{ PUI based forecast } \\
\cline { 2 - 10 } & TOTAL & GOV & PRIVATE & TOTAL & GOV & PRIVATE & TOTAL & GOV & PRIVATE \\
\cline { 2 - 10 } MSE & $\mathbf{0 . 0 0 0 0 7 4}$ & 0.000020 & $\mathbf{0 . 0 0 0 0 7 9}$ & 0.000341 & $\mathbf{0 . 0 0 0 0 1 6}$ & 0.000341 & 0.000176 & 0.000032 & 0.000143 \\
MAE & $\mathbf{0 . 0 0 7 1 3 9}$ & 0.004068 & $\mathbf{0 . 0 0 7 0 7 7}$ & 0.014770 & $\mathbf{0 . 0 0 3 3 7 8}$ & 0.015602 & 0.010282 & 0.004765 & 0.009906 \\
MAPE & $\mathbf{3 . 5 2 9 8 \%}$ & $10.5140 \%$ & $\mathbf{4 . 2 2 5 8 \%}$ & $7.5686 \%$ & $\mathbf{8 . 8 4 6 0 \%}$ & $9.9077 \%$ & $5.1818 \%$ & $12.1864 \%$ & $6.1638 \%$ \\
\cline { 2 - 10 } & \multicolumn{8}{c}{ With correlation regimes } \\
MSSE & $\mathbf{0 . 0 0 0 0 5 8}$ & $\mathbf{0 . 0 0 0 0 1 2}$ & $\mathbf{0 . 0 0 0 0 6 7}$ & 0.000228 & 0.000016 & 0.000271 & 0.000095 & 0.000021 & 0.000105 \\
MAE & $\mathbf{0 . 0 0 6 0 4 8}$ & $\mathbf{0 . 0 0 2 3 8 4}$ & $\mathbf{0 . 0 0 5 9 5 3}$ & 0.012197 & 0.003058 & 0.013063 & 0.008385 & 0.003557 & 0.008435 \\
MAPE & $\mathbf{2 . 9 9 0 3 \%}$ & $\mathbf{6 . 1 1 2 1 \%}$ & $\mathbf{3 . 5 4 0 7 \%}$ & $6.2184 \%$ & $7.8850 \%$ & $8.3495 \%$ & $4.0785 \%$ & $8.8672 \%$ & $5.1617 \%$ \\
\hline Bold face fonts present the best performing model. & Note: TOTAL = total investments, GOV = governmental investments, PRIVATE = private investments. \\
\hline
\end{tabular}


Table 4: MCS $p$-values

\begin{tabular}{|c|c|c|c|c|c|c|c|c|c|}
\hline & \multicolumn{3}{|c|}{ CSI based forecast } & \multicolumn{3}{|c|}{ PMI based forecast } & \multicolumn{3}{|c|}{ PUI based forecast } \\
\hline & TOTAL & GOV & PRIVATE & TOTAL & GOV & PRIVATE & TOTAL & GOV & PRIVATE \\
\hline & \multicolumn{9}{|c|}{ Without correlation regimes } \\
\hline MSE & 0.063 & 0.302 & 0.389 & 0.002 & 0.696 & 0.000 & 0.017 & 0.005 & 0.154 \\
\hline MAE & 0.017 & 0.000 & 0.097 & 0.000 & 0.087 & 0.000 & 0.013 & 0.000 & 0.033 \\
\hline \multirow[t]{2}{*}{ MAPE } & 0.015 & 0.000 & 0.099 & 0.000 & 0.089 & 0.000 & 0.014 & 0.000 & 0.033 \\
\hline & \multicolumn{9}{|c|}{ With correlation regimes } \\
\hline MSE & 1.00 & 1.00 & 1.00 & 0.004 & 0.696 & 0.013 & 0.063 & 0.405 & 0.389 \\
\hline MAE & 1.00 & 1.00 & 1.00 & 0.002 & 0.146 & 0.012 & 0.032 & 0.087 & 0.097 \\
\hline MAPE & 1.00 & 1.00 & 1.00 & 0.000 & 0.146 & 0.012 & 0.031 & 0.089 & 0.097 \\
\hline
\end{tabular}

